\title{
Game On framework: design participativo na elaboração de estratégias de gamificação aplicadas ao processo de ensino- aprendizagem
}

\section{Game On framework: participatory design in the development of gamification strategies applied to the teaching-learning process}

Isadora Burmeister Dickie, Univille.

isadora.dickie@gmail.com

Haro Ristow Wippel Schulenburg, Univille.

harodesigner@gmail.com

Luiz Paulo de Lemos Wiese, Univille.

luizwiese@gmail.com

\begin{abstract}
Resumo
Este artigo apresenta um estudo sobre a utilização do design participativo no desenvolvimento de estratégias de gamificação aplicadas ao ensino-aprendizagem. Conduzido pelo método Design Science Research, o estudo visou a identificação, o desenvolvimento e a avaliação de um framework para auxiliar na condução do processo de gamificação. Assim, as etapas do estudo compreenderam: (1) Identificação do problema: a partir das Revisões Bibliográficas Sistemática e Assistemática, levantou-se informações a respeito da participação dos demandantes no desenvolvimento de gamificação aplicada ao ensino-aprendizagem; (2) Definição dos resultados esperados: compreendeu à listagem de requisitos específicos ao processo participativo de gamificação; (3) Projeto e desenvolvimento: correspondeu à elaboração do framework; (4) Avaliação: correspondeu à realização de teste e refinamento do framework; e (5) Comunicação: correspondeu à socialização dos resultados do estudo e a sua utilização pela equipe do Projeto Game On que, desde 2019, integra atividades de ensino, pesquisa e extensão na Univille.
\end{abstract}

Palavras-chave: gamificação, design participativo, Design Science Research

\begin{abstract}
This paper presents a study on the use of participatory design in the development of gamification strategies applied to teaching-learning. Conducted by the Design Science Research method, the study aimed at identifying, developing and evaluating a framework to assist in conducting the gamification process. Thus, the stages of the study comprised: (1) Identification of the problem: from the systematic and unsystematic bibliographic reviews, information was raised regarding the participation of the applicants in the development of gamification applied to teachinglearning; (2) Definition of expected results: comprised the listing of specific requirements for the participatory gamification process; (3) Design and development: corresponded to the elaboration of the framework; (4) Evaluation: corresponded to testing and refining the framework; and (5) Communication: corresponded to the socialization of the study results and its use by the Game On Project team, which, since 2019, integrates teaching, research and extension activities at Univille.
\end{abstract}

Keywords: gamification, participatory design, Design Science Research 


\section{Introdução}

O presente estudo foi desenvolvido no âmbito do Projeto Integrado Game On que, desde 2019, integra atividades de ensino, pesquisa e extensão na Univille. O Projeto Game On tem por objetivo planejar, desenvolver e implementar estratégias e atividades de ensino gamificadas, a partir de demandas oriundas de professores atuantes nas redes pública e privada de ensino, com o intuito de auxiliar no desenvolvimento da criatividade, emancipação, desenvolvimento técnico e qualificação dos estudantes. A equipe do Projeto Game On é formada por docentes pesquisadores e acadêmicos bolsistas. Dentre as metas estipuladas pelo Projeto Game On está a elaboração de procedimentos próprios - e participativos - de desenvolvimento das estratégias gamificadas.

$\mathrm{Na}$ literatura científica, o termo Gamificação (Gamification) é relativamente novo, sendo a primeira aparição datada de 2010 (Çeker \& Özdamh, 2017). E, como toda novidade, sua utilização demanda um tempo de acomodação e assimilação para um entendimento uniforme pela sociedade. Hoje temos divergências no que gamificação significa e como deve ser trabalhada. Se por um lado o objetivo principal dos jogos é divertir o usuário, o da gamificação é mudar as atitudes e o comportamento do usuário (Çeker \& Özdamh, 2017). Embora esses conceitos - jogos e gamificação - tenham muito em comum, eles são diferentes e não devem ser confundidos.

Considerando as definições de jogo dadas por Salen \& Zimmerman (2003 apud Hitchens \& Tulloch, 2018) e Deterding et al. (2011 apud Hitchens \& Tulloch, 2018), ambas envolvem componentes como regras, resultados quantificáveis e a participação de, pelo menos, um usuário ativo. Porém, as definições dão pouca orientação sobre os elementos que os compõem. Ao mesmo tempo, cada componente (regras, resultados e usuário) pode ser encontrado em atividades não relacionadas a jogo. Se por um lado isso é útil para a gamificação, pois implica que elementos de jogos podem ser usados em contextos não relacionados a jogos, por outro lado, dificulta a tarefa de gamificação, pois fornece pouca orientação sobre o que pode ser usado e menos ainda sobre eficácia na aplicabilidade destes elementos.

Paralelo a isso, os estudantes do século XXI cresceram com a Internet, jogos e novas mídias, o que interfere na maneira como eles interagem e aprendem o conteúdo. Nesse contexto, as estratégias de ensino-aprendizagem devem se moldar ao público-alvo e evoluir junto com as mudanças de gerações. Temos hoje uma lentidão no processo de evolução do ensino que já não traz os resultados de aprendizagem alcançados em épocas anteriores. Precisamos evoluir com o ensino para manter ou, ainda mais desejável, melhorar a aprendizagem por meios criativos e inovadores. O uso da gamificação na educação, geralmente, concentra-se em aumentar o interesse dos estudantes pelos conteúdos e motivá-los a participar do processo de aprendizagem, além de estimular o pensamento crítico (Çeker \& Özdamh, 2017; Kingsley \& Grabner-Hager, 2017).

Embora a gamificação do aprendizado prometa um aumento da motivação e do envolvimento dos estudantes (Rideout et al. 2010 apud Kingsley \& Grabner-Hager, 2017), o desenvolvimento e a implementação da experiência de aprendizado exigem muito esforço (Dominguez et al. 2013 apud Mora et al., 2017). Para elaborar estratégias de gamificação para o ensino-aprendizagem é possível usar o conhecimento e os processos de design (Çeker \& Özdamh, 2017; Mora et al., 2017; Hung, 2018), visto que saber por quê, quando, onde e como usar a gamificação na educação precisa ser o mais claro possível e requer planejamento. Nesse sentido, considerar a participação 
das partes interessadas, principalmente dos professores e estudantes, na elaboração de estratégias de gamificação aplicadas ao ensino-aprendizagem traz mais lucidez e padronização para a construção mais homogênea de resultados. O Design Participativo, por sua vez, possui procedimentos e ferramentas que podem ser aplicados também a este processo.

Embora frequentemente tratado na literatura como um fenômeno recente, a participação das partes interessadas no processo de soluções a problemas existe por séculos (Martini et al., 2014), sendo a relevância destas práticas já mencionada nos séculos XVIII e XIX (Ferrari \& Fidanboylu, 2013). Ao longo do tempo, no entanto, a prática foi renovada e revisada à medida que a sociedade e a tecnologia evoluíram.

Numa visão geral dos níveis de participação das partes interessadas no desenvolvimento de soluções, Kaulio (1998) e Boukhris et al. (2017) separam a intensidade do envolvimento deles no processo: se a solução é pensada para eles, com eles ou por eles. Destes três níveis de intensidade da participação, os participantes atuariam: (a) como fonte de informação, para obtenção de dados específicos ou quando são consultados; (b) como cocriadores, quando elaboram junto, exteriorizando suas necessidades e dando opiniões; (c) como inovadores, quando podem desenhar ativamente suas próprias soluções.

Considerando o contexto apresentado, a questão que norteou esta pesquisa foi: qual/is procedimento/s pode/m ser utilizado/s pelo Projeto Game On na elaboração de estratégias de gamificação para o ensino-aprendizagem, considerando a participação do(s) público(s) envolvido(s)?

Nesse sentido, o objetivo deste estudo foi identificar, desenvolver e a avaliar um framework para auxiliar na condução do processo participativo de gamificação do Projeto Game On. Para tanto, utilizou-se do método da Design Science Research, compreendendo as etapas de identificação do problema; definição dos resultados esperados; projeto e desenvolvimento; avaliação; e comunicação.

Enfatiza-se que, como resultado deste estudo, mais do que adentrar nos pormenores dos elementos e mecânicas de jogos que podem ser utilizados nas estratégias de gamificação para o ensino-aprendizagem, o framework desenvolvido concentrou-se no detalhamento das etapas onde é necessária - e imprescindível - a participação dos públicos envolvidos (professores e estudantes).

\section{A participação das partes interessadas no desenvolvimento de estratégias de gamificação aplicadas ao ensino-aprendizagem}

De acordo com Çeker \& Özdamh (2017), o termo gamificação tem sido definido na literatura como sendo: (a) a utilização de mecanismos de jogos em aplicativos que não são de jogos, (b) a utilização do pensamento de jogo para resolver problemas, (c) a utilização de elementos de jogo aplicados a contextos de não-jogo e, mais relacionado ao ensino-aprendizagem (d) o envolvimento dos estudantes durante a atividade de aprendizagem de um conteúdo pedagógico. Neste último caso, e segundo os mesmos autores, ainda é comum haver confusão entre o termo gamificação com a aprendizagem baseada em jogos. 
A aprendizagem baseada em jogos corresponde a, simplesmente, aprender jogando e com jogos (Çeker \& Özdamh, 2017; Kingsley \& Grabner-Hager, 2017). De acordo com a Turkish Language Association (2017), jogo é definido como uma atividade divertida com certas regras que precisam ser seguidas - o que também ajuda a melhorar a inteligência e os talentos do usuário, além de ter momentos agradáveis. Já com a aplicação de estratégias de gamificação no ensinoaprendizagem, o aprendizado ocorre diferente de como acontece em uma atividade baseada em jogos, pois é preciso considerar os mecanismos que fornecem e apóiam o aprendizado, e as interações mútuas devem ser avaliadas na gamificação. Na gamificação, os estudantes não precisam ter jogos ou dispositivos eletrônicos, e nem sempre jogam jogos para aprender (Çeker \& Özdamh, 2017).

Em outras palavras, na aprendizagem baseada em jogos os estudantes chegam aos seus objetivos educacionais jogando, onde jogar geralmente assume o papel principal no processo de aprendizagem. Já a gamificação se materializa totalmente fora do contexto do jogo. Ou seja, com a gamificação, os jogos não substituem o processo de aprendizagem, mas a aplicação de elementos e mecanismos de jogos ajudam a tornar o ensino-aprendizagem uma atividade mais participativa, geralmente relacionada à experiência e ao envolvimento do estudante, e tem como objetivo superar as dificuldades de aprender.

O processo de desenvolvimento de estratégias de gamificação é bastante complexo, e não se resume a apenas usar a tríade 'pontos, medalhas e classificações' em aplicativos e/ou atividades (Çeker \& Özdamh, 2017; Hitchens \& Tulloch, 2018). Isso porque as estratégias de gamificação requerem, para além dos elementos de jogo, um esforço para mesclar princípios de ensinoaprendizagem na realização de tarefas complexas (Brunvand \& Hill, 2019). De acordo com Nicholson (2012 apud Hitchens \& Tulloch, 2018) uma estratégia de gamificação significativa leva em consideração os antecedentes que o estudante traz para a atividade e o contexto em que a atividade específica é colocada. Assim, um desafio na elaboração da gamificação é o desenvolvimento de estratégias para abranger uma variedade de experiências, desejos e habilidades dos estudantes (Nicholson, 2012 apud Hitchens \& Tulloch, 2018; Kingsley \& Grabner-Hager, 2017; Magro et al., 2019).

Nesse contexto, dentre as três principais abordagens para o desenvolvimento de estratégias de gamificação apresentadas por Mora et al. (2017) - a saber: (a) abordagem centrada no usuário; (b) abordagem centrada no jogo; e (c) abordagem centrada na tecnologia -, a que mais se aproxima da gamificação significativa, registrada em mais da metade das publicações revisadas pelos autores, é a abordagem centrada no usuário, onde o usuário e seus objetivos são o foco central do desenvolvimento das estratégias de gamificação. Isso não implica na restrição do uso de princípios e/ou tecnologia de design de jogos, mas significa que o usuário é o centro do processo de gamificação. Porém, ainda citando o mesmo estudo, a participação das partes interessadas no processo de elaboração das estratégias é considerada necessária em menos da metade dos trabalhos; o que contrasta com a ampla utilização dos fundamentos de interação, enfatizando a gamificação como uma experiência do usuário em si. Ora, se o processo de gamificação para o ensino-aprendizagem deve priorizar o foco no estudante (Botha \& Herselman, 2015; Hung, 2018) então, o envolvimento das partes interessadas no desenvolvimento das estratégias de gamificação não pode ser negligenciado, principalmente a dos professores demandantes. 
O estudo de Huang \& Soman (2013 apud Magro et al., 2019) corrobora com a necessidade de participação dos usuários no processo de gamificação, afirmando que os passos para gamificar o ensino-aprendizagem são: (i) analisar o perfil dos estudantes e o contexto; (ii) definir os objetivos de aprendizagem; (iii) estruturar a experiência do estudante; (iv) identificar os recursos disponíveis e aplicar as estratégias de gamificação adequadas. Nesse sentido, para analisar o perfil do estudante e o contexto, bem como para estruturar a experiência do estudante, a utilização de processos participativos se faz pertinente.

Para análise do perfil do estudante e do contexto, seguindo a proposta de Baldeón et al. (2017), tem-se, no quadro 01, a definição dos tipos de "jogadores" e os estilos de aprendizagem.

\begin{tabular}{|c|c|c|}
\hline & TIPOS & CARACTERÍSTICAS \\
\hline \multirow{4}{*}{ ESTILOS DE APRENDIZAGEM } & Ativo & $\begin{array}{l}\text { Prefere atividades onde aprenda } \\
\text { fazendo. }\end{array}$ \\
\hline & Pragmático & $\begin{array}{l}\text { Prefere ver a aplicabilidade no } \\
\text { mundo real. }\end{array}$ \\
\hline & Teórico & Prefere conteúdos teóricos. \\
\hline & Reflexivo & Prefere o abstrato e o dedutivo. \\
\hline \multirow{6}{*}{ TIPOS DE JOGADORES } & Filantropos & Não esperam nada em troca. \\
\hline & Socializadores & $\begin{array}{l}\text { Gostam da interação e do } \\
\text { relacionamento com os outros. }\end{array}$ \\
\hline & Espíritos livres & $\begin{array}{l}\text { Gostam de oportunidades de } \\
\text { explorar a si mesmos. }\end{array}$ \\
\hline & Competitivos & Buscam desenvolvimento pessoal. \\
\hline & Jogadores & Buscam recompensas. \\
\hline & Reativos & $\begin{array}{l}\text { Buscam mudanças, questionam o } \\
\text { sistema. }\end{array}$ \\
\hline
\end{tabular}

Quadro 01 - Tipos de "jogadores" e os estilos de aprendizagem. Fonte: Baseado em Baldeón et al. (2017).

Considerando os tipos de perfis de "jogadores" e estilos de aprendizagem apresentados no quadro 01, Magro et al. (2019) sugerem ser conveniente aplicar um questionário aos estudantes a fim de coletar informações sobre essas variáveis. Segundo os autores, isso permitirá adaptar as estratégias de gamificação ao perfil dos estudantes, orientando-as para a obtenção dos objetivos de aprendizagem. A sugestão de Magro et al. (2019) em envolver os estudantes, nesse sentido, aproxima o desenvolvimento de estratégias de gamificação a um processo participativo.

Para além do envolvimento dos estudantes no processo de desenvolvimento de estratégias de gamificação para o ensino-aprendizagem, Botha \& Herselman (2015) e Hung (2018) enfatizam que o envolvimento dos professores auxilia, em particular, na tomada de decisões que envolvem quais comportamentos são recompensados ou penalizados, como o sistema gamificado é 
apresentado e como os estudantes devem interagir. Isso porque é o professor que conhece melhor o público e o contexto para/no qual a gamificação será destinada.

Importante ressaltar que o Design Participativo aplicado ao desenvolvimento de estratégias de gamificação para o ensino-aprendizagem no contexto do Projeto Game On vai de encontro ao que sugerem Schmitz \& Dickie (2017), onde o modelo participativo permite que profissionais de outras áreas ou até mesmo usuários finais sejam incluídos no projeto de maneira a colaborar ativamente com a equipe de trabalho. Neste modelo, o envolvimento das partes interessadas vai mais além de apenas servirem de fonte de informação.

\section{Procedimentos metodológicos}

O presente estudo foi realizado por meio da aplicação do método da Design Science Research (DSR), executado a partir da adaptação das etapas propostas por Lacerda et al. (2013), a saber: (1) Identificação do problema; (2) Definição dos resultados esperados; (3) Projeto e desenvolvimento; (4) Avaliação; e (5) Comunicação. O quadro 02 apresenta os procedimentos metodológicos utilizados em cada uma das etapas.

\begin{tabular}{|c|c|}
\hline ETAPAS DA DSR & PROCEDIMENTOS METODOLÓGICOS \\
\hline (1) Identificação do problema & $\begin{array}{l}\text { - } \quad \text { Revisão Bibliográfica Sistemática (RBS); } \\
\text { - } \quad \text { Revisão Bibliográfica Assistemática (RBA); } \\
\text { - } \text { Observação Participante (Atendimento às reuniões da } \\
\text { equipe do Projeto Game On). }\end{array}$ \\
\hline (2) Definição dos resultados esperados & $\begin{array}{l}\text { - Diagrama de Afinidade; } \\
\text { - Lista de Requisitos. }\end{array}$ \\
\hline (3) Projeto e desenvolvimento & $\begin{array}{l}\text { - Geração de Alternativas; } \\
\text { - } \quad \text { Proposição do framework inicial. }\end{array}$ \\
\hline (4) Avaliação & $\begin{array}{l}\text { - Observação Participante (Teste: aplicação em demanda } \\
\text { de gamificação do Projeto Game On); } \\
\text { - Refinamentos: adequação do framework de acordo com } \\
\text { os resultados do teste. }\end{array}$ \\
\hline (5) Comunicação & $\begin{array}{l}\text { - Socialização dos resultados do estudo para a equipe do } \\
\text { Projeto Game On; } \\
\text { - Utilização do framework como metodologia própria e } \\
\text { participativa do Projeto Game On. }\end{array}$ \\
\hline
\end{tabular}

Quadro 02 - Etapas da DSR e os respectivos procedimentos metodológicos utilizados no estudo. Fonte: Desenvolvido pelos autores (2020).

Seguindo os procedimentos sugeridos por Conforto et al. (2011), a Revisão Bibliográfica Sistemática (RBS), compreendeu a busca por trabalhos científicos e acadêmicos desenvolvidos a respeito do tema gamificação aplicada ao ensino-aprendizagem. Assim, o termo de busca 'gamificação + ensino-aprendizagem' foi aplicado no sistema de busca avançada do Portal de Periódicos CAPES (https://www.periodicos.capes.gov.br/), considerando os seguintes critérios:

(i) critérios de inclusão:

(i.a) tipo de material: artigos (apenas em periódicos revisados por pares);

(i.b) data de publicação: últimos cinco anos; 
(i.c) idioma: inglês;

(ii) critérios de qualificação:

(ii.a) trazer definição dos termos citados (gamificação e ensino-aprendizagem);

(ii.b) trazer exemplos práticos e resultados de aplicações ou análises sobre casos de gamificação para o ensino-aprendizagem na modalidade presencial.

Ao todo, 725 artigos foram encontrados. Destes, 37 foram selecionados para leitura, a partir da aplicação dos critérios de inclusão e qualificação. A conclusão da RBS correspondeu à sistematização do conteúdo que, complementada com uma Revisão Bibliográfica Assistemática (RBA), resultou na fundamentação teórica apresentada neste artigo.

Outro procedimento utilizado na etapa (1), Identificação do problema, foi a Observação Participante (OP). De acordo com Marshall \& Rossman (1995) e Vogt (1999), a OP corresponde a uma técnica de coleta de dados onde o pesquisador participa como membro do grupo que está estudando. Assim, os pesquisadores acompanharam os encontros da equipe do Projeto Game On, no período de maio a setembro de 2019, onde foi possível observar tanto as especificidades da demanda de gamificação como as necessidades da equipe do projeto com relação aos recursos e às atividades a serem desenvolvidas no processo de gamificação.

Na etapa seguinte, a definição de requisitos específicos para a elaboração de um processo de gamificação considerou tanto os resultados da RBS e da RBA quanto os da OP. Os requisitos definidos para a elaboração do framework estão apresentados no quadro 03.

Requisitos definidos para o framework:

1. Prever um momento de preparação: alinhamento da equipe do Projeto Game On após o recebimento da demanda.

2. Prever encontros/workshops para o desenvolvimento das demandas junto aos demandantes (co-criação).

3. Prever encontros para acompanhar a aplicação das estratégias de gamificação, atendendo a uma das metas do Projeto Game On, que é a de "formar" multiplicadores de gamificação para o ensino-aprendizagem.

Quadro 03 - Requisitos definidos para a elaboração do framework.

Fonte: Desenvolvido pelos autores (2020).

O framework elaborado foi testado no desenvolvimento de estratégias de gamificação aplicadas ao ensino-aprendizagem de uma das demandas recebidas pelo Projeto Game On. Após a finalização desta demanda, o framework foi refinado e os resultados apresentados aos integrantes do Projeto Game On. Estas ações corresponderam, respectivamente, à execução das etapas (3) Projeto e desenvolvimento, (4) Avaliação e (5) Comunicação - detalhadas no próximo tópico.

\section{Resultados}

Etapa (3) Projeto e desenvolvimento 
O desenvolvimento do framework inicial considerou os requisitos apresentados anteriormente. O quadro 04 apresenta as seis etapas estipuladas para o processo participativo de gamificação das demandas do Projeto Game On.

\begin{tabular}{|c|c|c|c|}
\hline \multirow{2}{*}{ Etapa } & \multirow{2}{*}{ Descrição } & \multicolumn{2}{|c|}{ Atores envolvidos } \\
\hline & & $\begin{array}{c}\text { Equipe } \\
\text { Game On }\end{array}$ & Demandante \\
\hline $\begin{array}{l}1 \text { - Mapeamento de } \\
\text { oportunidades }\end{array}$ & $\begin{array}{l}\text { Refere-se ao encontro da equipe Game On com o(s) } \\
\text { demandante(s) para conversar especificamente sobre } \\
\text { a demanda. Neste encontro, agendado previamente, } \\
\text { o(s) demandante(s) compartilha(m) com a equipe } \\
\text { Game On informações e materiais sobre o curso, a } \\
\text { disciplina, e/ou o tema que deseja gamificar. }\end{array}$ & $\mathrm{X}$ & $\mathrm{X}$ \\
\hline $\begin{array}{l}2 \text { - Análise das } \\
\text { oportunidades }\end{array}$ & $\begin{array}{l}\text { De posse das informações e materiais } \\
\text { disponibilizados pelo(s) demandante(s), a equipe } \\
\text { Game On analisa as oportunidades e possibilidades } \\
\text { para a aplicação da gamificação. }\end{array}$ & $\mathrm{X}$ & \\
\hline 3 - Cocriação & $\begin{array}{l}\text { Em um novo encontro com o(s) demandante(s), a } \\
\text { equipe Game On apresenta os resultados da análise } \\
\text { de oportunidades, indicando caminhos possíveis para } \\
\text { aplicação das estratégias de gamificação. Ao final } \\
\text { desta etapa, já é possível saber qual será a estratégia } \\
\text { de gamificação a ser aplicada, bem como os } \\
\text { materiais necessários para dar suporte a sua } \\
\text { aplicação. }\end{array}$ & $\mathrm{X}$ & $\mathrm{X}$ \\
\hline $\begin{array}{l}4 \text { - Elaboração de } \\
\text { materiais }\end{array}$ & $\begin{array}{l}\text { Nesta etapa, a equipe Game On elabora os materiais } \\
\text { necessários para a aplicação das estratégias de } \\
\text { gamificação. Importante ressaltar que os materiais } \\
\text { desenvolvidos são personalizados, de acordo com a } \\
\text { demanda. }\end{array}$ & $\mathrm{X}$ & \\
\hline 5 - Capacitação & $\begin{array}{l}\text { Refere-se à entrega dos materiais desenvolvidos para } \\
\text { o(s) demandante(s) e à explicação de como aplicá- } \\
\text { los no contexto da estratégia de gamificação } \\
\text { elaborada na etapa de cocriação. }\end{array}$ & $\mathrm{X}$ & $\mathrm{X}$ \\
\hline $\begin{array}{l}6 \text { - Aplicação e } \\
\text { acompanhamento }\end{array}$ & $\begin{array}{l}\text { Refere-se à aplicação da estratégia de gamificação } \\
\text { propriamente dita e o acompanhamento dos } \\
\text { resultados para avaliação da necessidade de ajustes. }\end{array}$ & $\mathrm{X}$ & $X$ \\
\hline
\end{tabular}

\section{Quadro 04 - Framework inicial.}

Fonte: Desenvolvido pelos autores (2020).

De acordo com o quadro 04, o framework inicial possui seis etapas, das quais quatro prevêem a participação das partes interessadas; ou seja, da equipe do Projeto Game On composta por três docentes pesquisadores e cinco bolsistas de graduação e o(s) demandante(s). Este processo, então, foi aplicado no atendimento a uma demanda do Projeto Game On, correspondendo à etapa (4), avaliação, apresentada a seguir.

\section{Etapa (4) Avaliação}

A demanda atendida pelo Projeto Game On correspondeu a uma solicitação da Secretaria Municipal de Educação da cidade de Joinville, através da Escola Municipal Professora Ada Sant'anna da Silveira. 
Para o atendimento desta demanda, a ação inicial da equipe do Projeto Game On foi a realização de uma reunião de apresentação do projeto (figura 01), onde estavam presentes, além da equipe do projeto, a professora da disciplina de história do sexto ano do ensino fundamental, o supervisor pedagógico da escola, a assessora da Secretaria de Educação e os pesquisadores. A reunião durou cerca de uma hora e, a partir disso, uma outra reunião foi marcada, a fim de alinhar a demanda e as expectativas com relação aos procedimentos do desenvolvimento da estratégia de gamificação. Apesar da ação não ter sido planejada no framework inicial, sua realização foi extremamente importante, visto que, para que ocorra a demanda, o Projeto Game On precisa ser apresentado ao seu público-alvo.

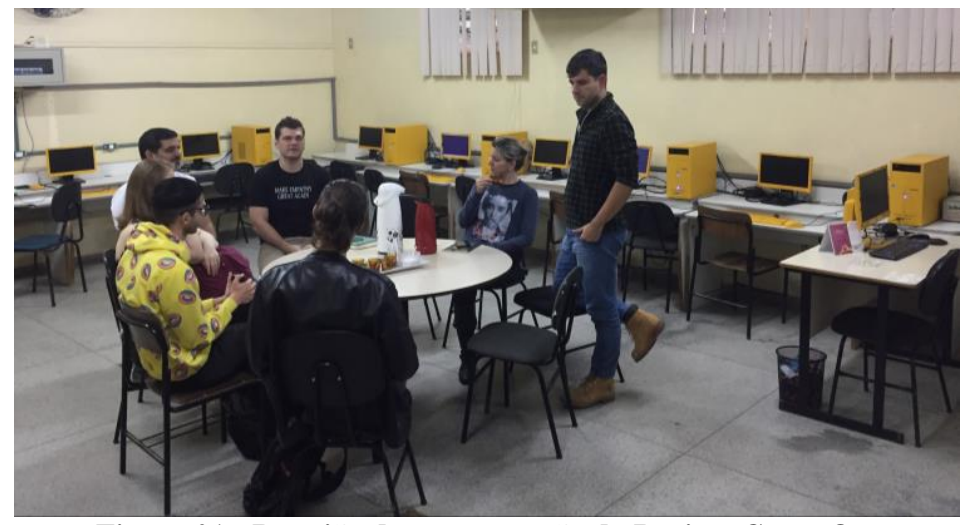

Figura 01 - Reunião de apresentação do Projeto Game On. Fonte: Arquivo do Projeto Game On (2019).

Na segunda reunião, que durou cerca de duas horas, a equipe do Projeto Game On, composta por acadêmicos bolsistas e professores pesquisadores, realizou a captação da demanda, utilizando como instrumento de coleta de dados um formulário de Briefing, apresentado no quadro 05. Assim, definiu-se que seria realizada a gamificação do conteúdo sobre a história do Egito Antigo.

Formulário de Briefing sobre a demanda:

\begin{tabular}{|c|c|}
\hline Público-alvo da ação: & Estudantes do $6^{\circ}$ ano do Ensino Fundamental. \\
\hline Número de turmas: & 02 turmas do período matutino. \\
\hline $\begin{array}{l}\text { Número total de } \\
\text { estudantes: }\end{array}$ & 70 \\
\hline Disciplina(s) Envolvida(s): & História \\
\hline Tema(s): & Egito Antigo \\
\hline $\begin{array}{l}\text { Tempo de duração de } \\
\text { abordagem do conteúdo: }\end{array}$ & 01 trimestre \\
\hline $\begin{array}{l}\text { Material(is) Didático(s) } \\
\text { utilizado(s) nas aulas: }\end{array}$ & Livros didáticos. \\
\hline $\begin{array}{l}\text { Espaço(s) Existente(s) na } \\
\text { Escola: }\end{array}$ & $\begin{array}{l}\text { Biblioteca; } \\
\text { Pátio; } \\
\text { Refeitório; } \\
\text { Salas de Aula Fixa; }\end{array}$ \\
\hline
\end{tabular}




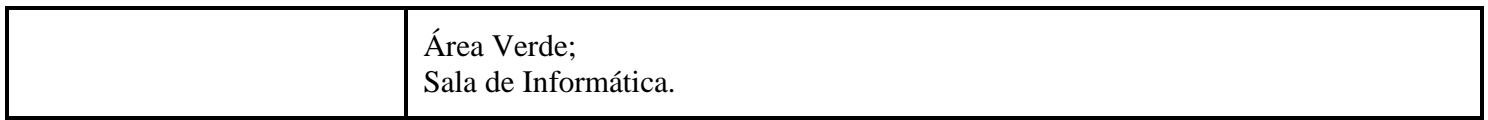

Quadro 05 - Formulário de Briefing para captação de demanda.

Fonte: Arquivo do Projeto Game On (2019).

Com as informações detalhadas da demanda, a equipe do Projeto Game On realizou o mapeamento do problema, que consistiu na utilização das ferramentas Cartões de Insights e Diagrama de Afinidades (figura 02). A aplicação destas ferramentas significou a análise das oportunidades; ou seja, auxiliou a equipe do Projeto Game On a na geração dos primeiros insights a respeito das possibilidades para a gamificação do tema proposto pela professora.

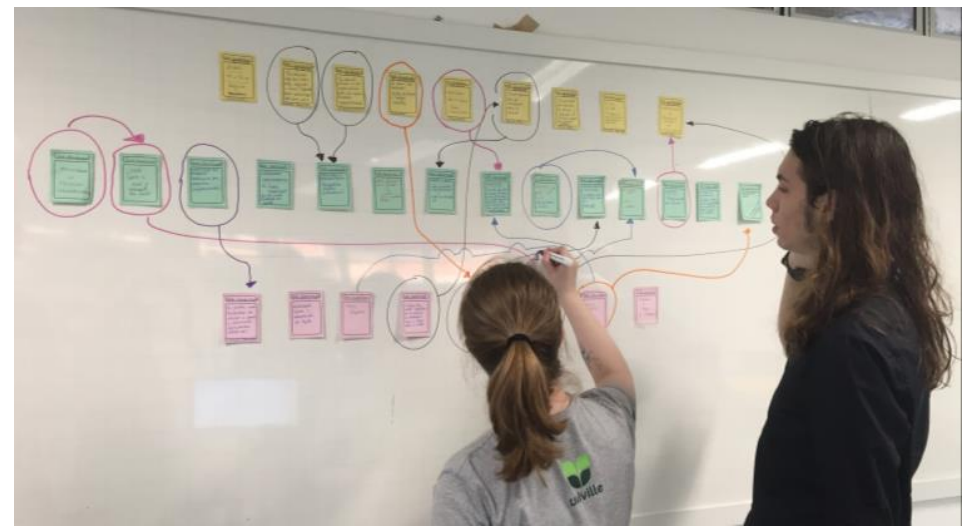

Figura 02 - Aplicação das ferramentas Cartões de Insights e Diagrama de Afinidades. Fonte: Arquivo do Projeto Game On (2019).

A ação seguinte correspondeu à realização de sessões de cocriação com a professora e o supervisor pedagógico. Para tanto, a equipe do Projeto Game On realizou workshops onde foi utilizado um conjunto de ferramentas de cocriação, selecionado e adaptado pela própria equipe do projeto para o atendimento de demandas de gamificação. As sessões de cocriação tiveram que ser divididas em dois workshops, sendo as atividades realizadas apresentadas no quadro 06.

\begin{tabular}{|c|c|c|}
\hline Informações do workshop & Ferramentas utilizadas & Atividades \\
\hline $\begin{array}{l}\text { Workshop } 01 \\
\text { Data: } 15 \text { de agosto de } 2019 . \\
\text { Duração: } 2 \mathrm{~h}\end{array}$ & $\begin{array}{ll}\text { - } \quad \text { Mapa de Empatia; } \\
\text { - } \quad \text { Jnálise SWOT; } \\
\text { Jornada do Usuário. }\end{array}$ & $\begin{array}{l}\text { Neste primeiro workshop de cocriação, o objetivo } \\
\text { foi apresentar para a professora os primeiros } \\
\text { insights trazidos pela equipe do Projeto Game On. } \\
\text { Assim, a equipe apresentou as informações e iniciou } \\
\text { a aplicação da ferramenta Mapa de Empatia, que } \\
\text { teve por objetivo fazer com que a professora } \\
\text { pudesse registrar as principais características dos } \\
\text { seus estudantes. } \\
\text { Após, a ferramenta Análise SWOT foi aplicada com } \\
\text { o intuito de registrar as principais características da } \\
\text { professora (forças e fraquezas) e as principais } \\
\text { características relacionadas a sua experiência com o } \\
\text { ensino-aprendizagem naquelas turmas } \\
\text { (oportunidades e ameaças). } \\
\text { Após o preenchimento das informações de ambas as } \\
\text { ferramentas, houve a discussão das informações e } \\
\text { dos insights iniciais apresentados pela equipe do } \\
\text { Projeto Game On. A partir desta discussão, novos } \\
\text { insights surgiram. }\end{array}$ \\
\hline
\end{tabular}




\begin{tabular}{|l|l|l|}
\hline & & $\begin{array}{l}\text { A ferramenta Jornada do Usuário auxiliou, então, no } \\
\text { preenchimento dos objetivos da gamificação, bem } \\
\text { como as etapas e atividades de ensino-aprendizagem } \\
\text { que seriam gamificadas. }\end{array}$ \\
\hline & - Octálise. & $\begin{array}{l}\text { Neste segundo workshop de cocriação, as } \\
\text { informações preenchidas na ferramenta Jornada do } \\
\text { Usuário foram discutidas e refinadas, à medida que } \\
\text { a ferramenta Octálise ia sendo explicada. } \\
\text { A ferramenta Octálise corresponde à um framework } \\
\text { de gamificação, baseado nos princípios do Design } \\
\text { Centrado no Usuário, desenvolvido por Chou (web, } \\
\text { 2020). Esta ferramenta traz oito unidades de } \\
\text { gamificação, as quais foram utilizadas para a } \\
\text { Data: } 22 \text { de agosto de 2019. } \\
\text { Duração: } 2 \mathrm{~h}\end{array}$ \\
$\begin{array}{ll}\text { operacionalização das estratégias definidas na } \\
\text { aplicação da ferramenta Jornada do Usuário. }\end{array}$ \\
\hline
\end{tabular}

Quadro 06 - Atividades e ferramentas utilizadas nos workshops de cocriação. Fonte: Dos autores (2020).

A partir da realização dos workshops de cocriação (figura 03), as estratégias de gamificação foram definidas e a equipe do Projeto Game On iniciou o desenvolvimento dos materiais de apoio à aplicação das estratégias.
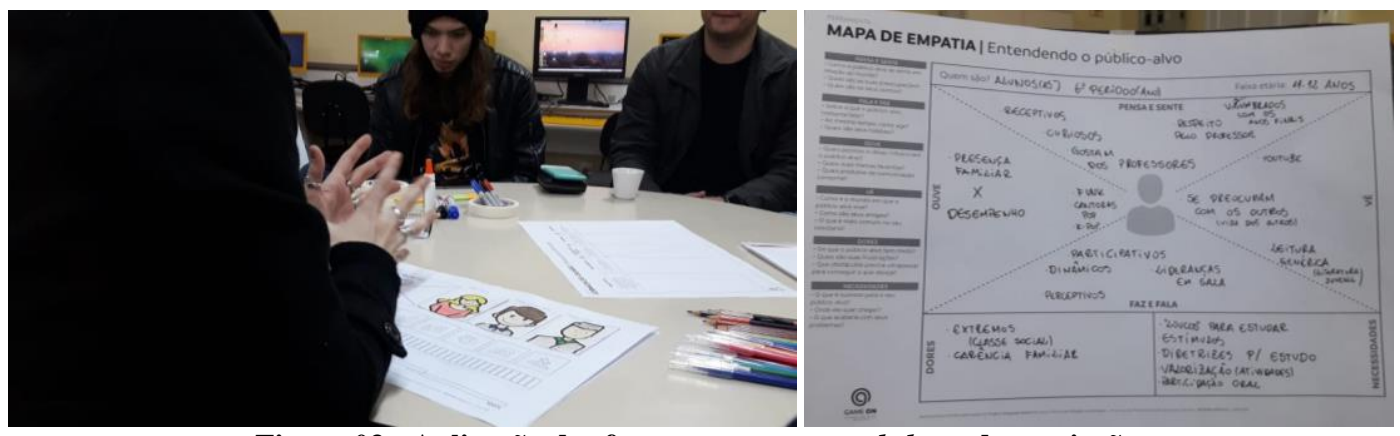

Figura 03 - Aplicação das ferramentas nos workshops de cocriação.

Fonte: Arquivo do Projeto Game On (2019).

Os materiais desenvolvidos foram entregues para a professora demandante, e na mesma ocasião, a equipe do Projeto Game On explicou para a mesma como os materiais deveriam ser utilizados.

As estratégias de gamificação elaboradas foram aplicadas em torno de uma narrativa baseada na história do Egito Antigo, onde os estudantes receberam a visita da Rainha Cleópatra. Vinda do passado, solicita ajuda, pois o legado do povo egípcio da antiguidade estava correndo perigo de ser esquecido (Figura 04). 


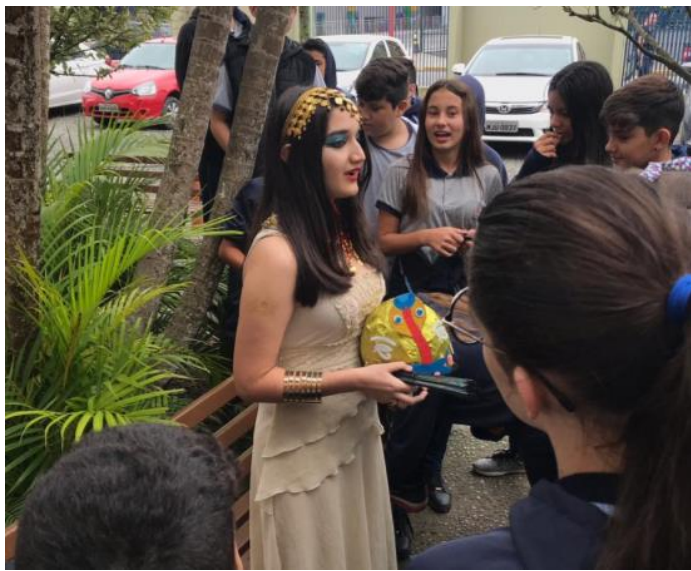

Figura 04 - Acompanhamento da aplicação das estratégias de gamificação desenvolvidas: Rainha Cleópatra chega na Escola para dar uma missão aos estudantes (encenação teatral).

Fonte: Arquivo do Projeto Game On (2019).

Os estudantes, então, receberam a primeira missão, que consistiu na formação de equipes e na escolha de um deus egípcio da antiguidade para guiá-las na execução das próximas missões (Figura 05). Outras missões recebidas foram a elaboração de maquetes e máscaras, textos em papiro, dentre outras.

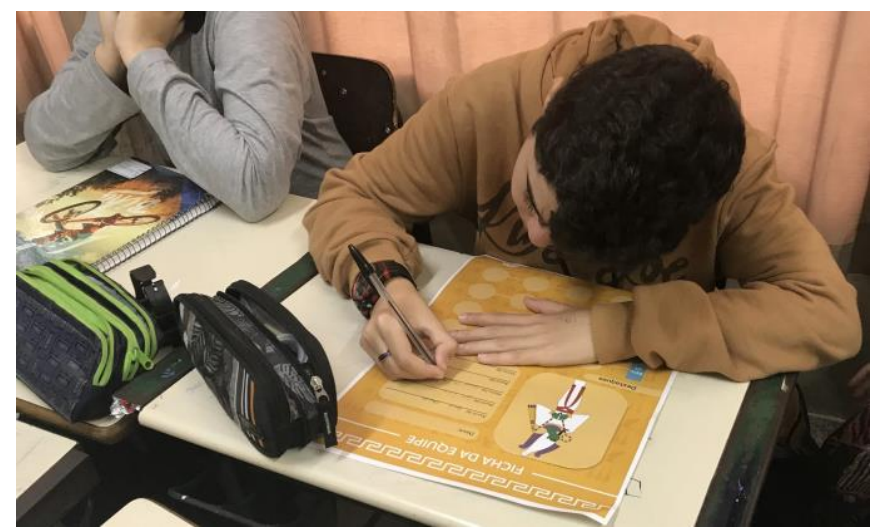

Figura 05 - Acompanhamento da aplicação das estratégias de gamificação desenvolvidas: Atividade realizada com os Estudantes para preenchimento da Ficha da Equipe (material produzido pela Equipe do Projeto Game On). Fonte: Arquivo do Projeto Game On (2019).

Ao cumprir cada missão, as equipes eram agraciadas com hieróglifos, que iam sendo colocados em um painel fixado na parede da sala de aula (Figura 06). Ao final da abordagem do conteúdo, foi possível decifrar a mensagem final da Rainha Cleópatra: "Vocês salvaram a história do Egito Antigo". 

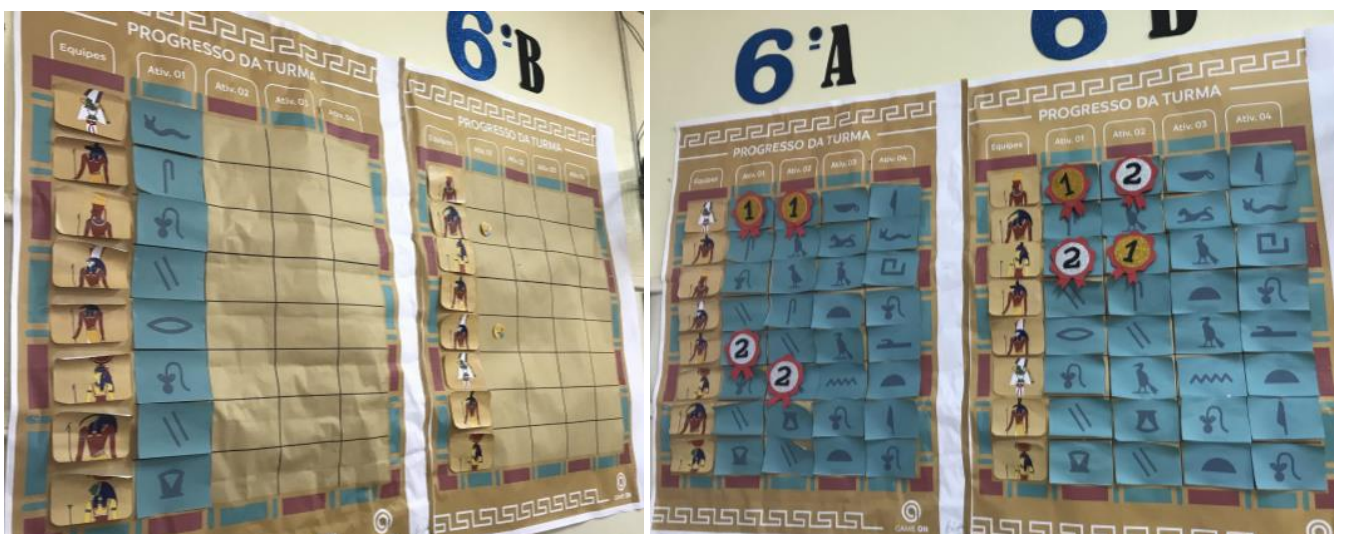

Figura 06 - Acompanhamento da aplicação das estratégias de gamificação desenvolvidas: Painel de progresso por equipe, inicial e final (material produzido pela Equipe do Projeto Game On).

Fonte: Arquivo do Projeto Game On (2019).

O feedback da professora demandante, após a finalização da aplicação das estratégias de gamificação, foi coletado através de suas respostas a um formulário, dividido em três seções: (1) Identificação da demandante e da demanda; (2) Avaliação do processo de desenvolvimento das estratégias de gamificação e (3) Avaliação da aplicação das estratégias de gamificação. Na figura 07 estão apresentadas as respostas da professora demandante às seções 2 e 3.

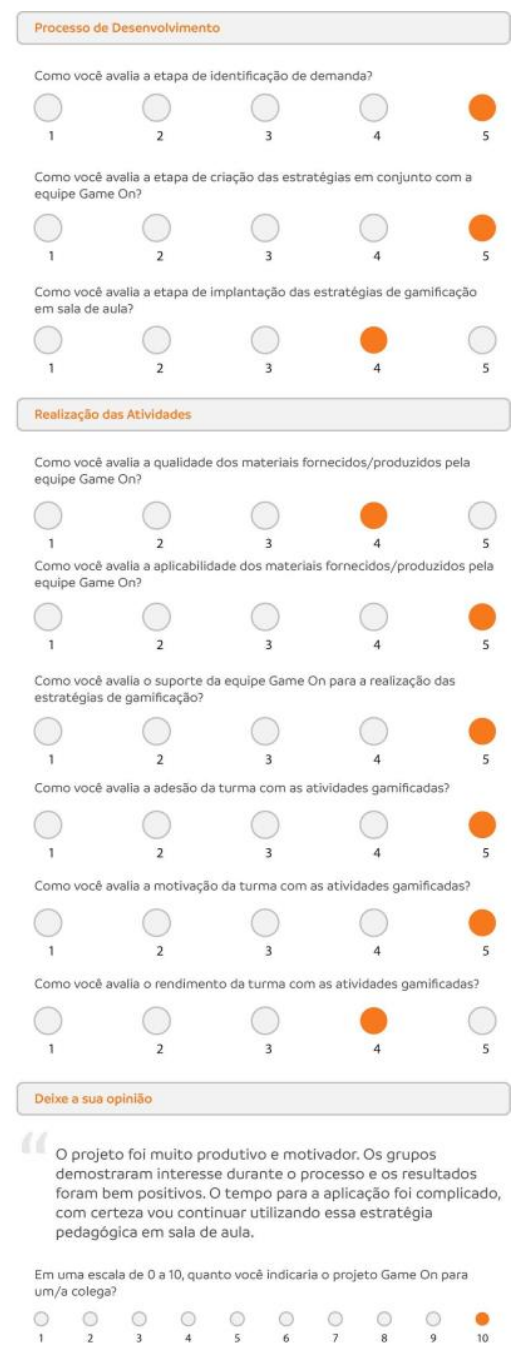

Figura 07 - Feedback da professora demandante, coletado através de formulário.

Fonte: Arquivo do Projeto Game On (2019). 
A partir do exposto, avalia-se que a aplicação do framework inicial no desenvolvimento das estratégias de gamificação foi eficaz. Os workshops de cocriação foram fundamentais neste processo, onde a participação da professora demandante na elaboração das estratégias foi essencial devido ao seu conhecimento sobre os antecedentes dos seus estudantes, bem como do contexto e das possibilidades de realização de atividades específica. Por exemplo, a ideia de convidar uma estudante de uma outra turma e outro ano, mas da mesma escola, para representar o papel da Rainha Cleópatra, foi da professora; assim como a informação de que os estudantes achariam a ação da própria narrativa motivadora.

Por outro lado, percebeu-se que a professora demandante se sentiu insegura durante a utilização dos materiais de suporte às atividades, tais como a entrega dos hieróglifos a cada missão realizada pelos estudantes, por ter sido a primeira vez que utilizava e aplicava tais materiais. Mesmo que a Equipe do Projeto Game On tenha oferecido suporte e acompanhando a execução das atividades, nem sempre foi possível estar em todos os momentos com a professora. Isso mostra o quão importante é inserir as partes interessadas no processo de desenvolvimento das estratégias gamificadas, mas, mais ainda, de capacitá-las para a aplicação dos materiais.

Após a análise do caso onde o framework inicial foi aplicado, os pesquisadores perceberam a necessidade de incluir uma etapa anterior à etapa 01: a de entrar em contato com o demandante previamente. Esta etapa é necessária tendo em vista os objetivos do Projeto Game On de gerar autonomia pedagógica ao professor e torná-lo um multiplicador dos processos de gamificação como estratégia de motivação e engajamento para o ensino e aprendizagem. Assim, para que o Projeto Game On possa atender demandas e gerar autonomia, este primeiro contato é crucial para que professores, de qualquer nível de ensino, possam conhecer melhor o projeto. com a inclusão desta etapa, o framework foi finalizado, e o resultado pode ser observado na figura 08 .

A partir da definição do framework final, a etapa (5), comunicação, correspondeu à apresentação à equipe do Projeto Game On, de maneira que seus integrantes, professores pesquisadores e acadêmicos bolsistas, pudessem ter conhecimento de como o processo de atendimento às demandas seguintes deveriam ocorrer. 


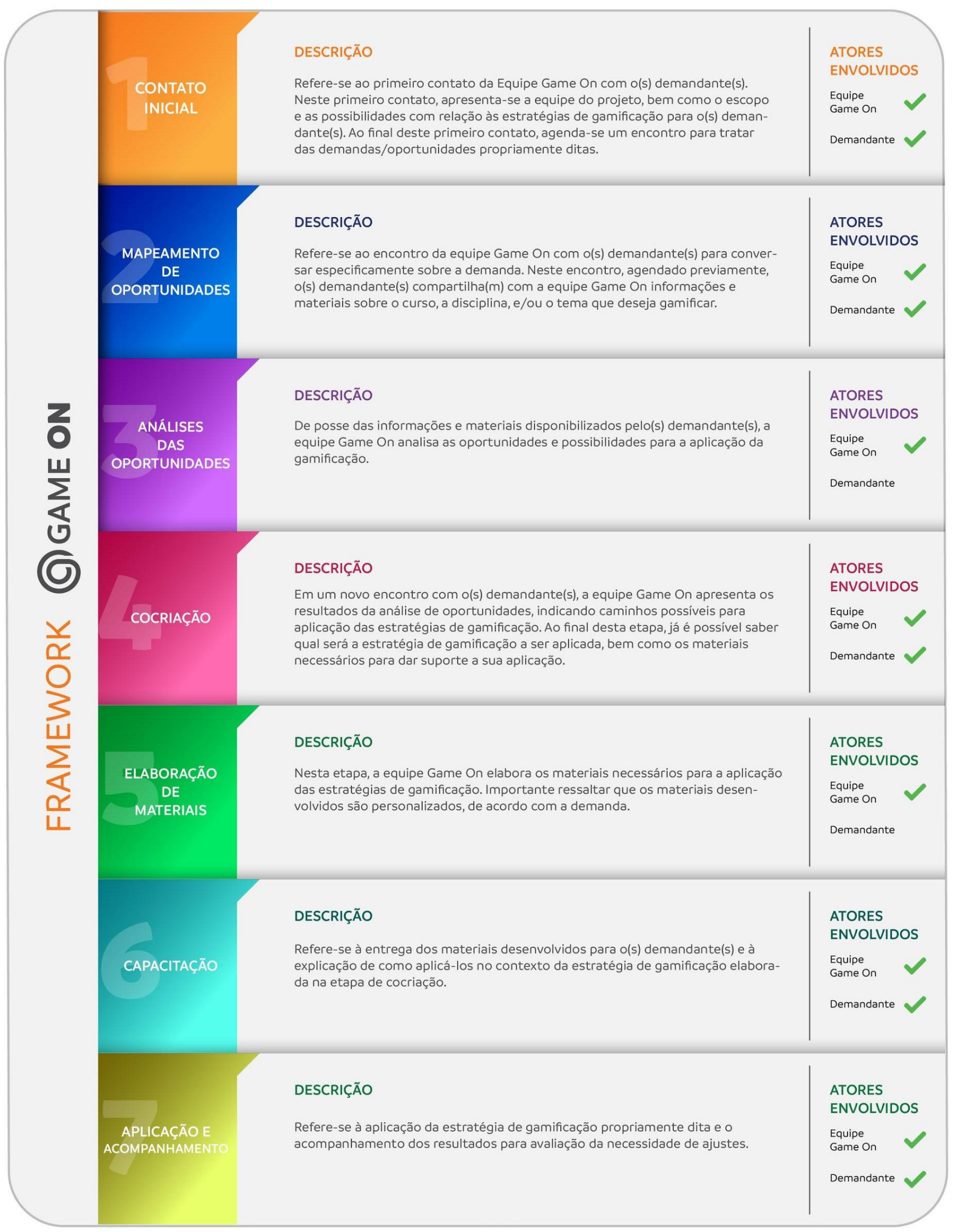

Figura 08 - Framework final.

Fonte: Desenvolvido pelos autores (2020). 


\section{Considerações finais}

A gamificação mostra-se como possibilidade para atualização de práticas pedagógicas, principalmente relacionadas ao aumento da motivação e engajamento dos estudantes, pois utiliza elementos e mecânicas de jogos no contexto do ensino-aprendizagem. A aplicação da gamificação ao contexto pedagógico, no entanto, não deve ser confundida com a aplicação de jogos, simplesmente. Ao contrário: a elaboração de estratégias de gamificação para o ensinoaprendizagem requerem uma análise do contexto onde serão aplicadas, incluindo a análise do(s) público(s) para o(s) qual(is) serão destinadas, sem esquecer, ainda, dos objetivos e atividades envolvidas no planejamento das atividades. Por estes motivos, é essencial envolver as partes interessadas, sobretudo professores e estudantes, no desenvolvimento de tais estratégias. $\mathrm{O}$ envolvimento da professora demandante, no caso apresentado, correspondeu ao nível de participação como cocriadora, elaborando e exteriorizando as necessidades e dando opiniões. Sem sua participação, as estratégias e atividades elaboradas poderiam não ter sido exitosas.

O desenvolvimento deste estudo, conduzido através do método da Design Science Research (DSR), resultou na elaboração de um framework para auxiliar na condução do processo participativo de gamificação do Projeto Integrado Game On. Os pesquisadores, também integrantes da equipe do projeto, acompanharam de perto as atividades do projeto, favorecendo o entendimento do problema e a elaboração da solução. A intenção é que este framework seja comunicado também aos demandantes, para que eles possam desenvolver suas próprias soluções. Neste caso, observa-se que ainda é necessário elucidar o que se trata a gamificação e como tais estratégias podem ser aplicadas, visto que, por ser algo relativamente novo, os professores demandantes ainda se sentem inseguros em inseri-las em seus processos de ensino-aprendizagem.

O framework elaborado tem o objetivo de conduzir o atendimento das demandas por gamificação do ensino-aprendizagem, em qualquer nível de Ensino, utilizando processos participativos. Assim, das sete etapas totais, cinco envolvem a participação de professores e/ou demandantes, sendo uma delas destinada à cocriação das estratégias, através da realização de workshops e da utilização de um conjunto de ferramentas. No entanto, é importante ressaltar a fluidez do framework e a sua capacidade de se adequar às novas necessidades que, após a continuidade de aplicação em outras demandas, será constantemente atualizado.

\section{Referências}

Baldeón, J.; Rodríguez, I.; Puig, A.; López-Sánchez, M. Evaluación y rediseño de una experiencia de gamificación en el aula basada en estilos de aprendizaje y tipos de jugador. In: Contreras, R.; Eguia, J. (Eds.). Experiencias de gamificación en aulas. Barcelona: Universitat Autònoma de Barcelona, 2017.

Botha, A.; Herselman, M. A Teacher Tablet Toolkit to meet the challenges posed by 21st century rural teaching and learning environments. In: South African Journal of Education, v. 35, n. 4, 2015.

Boukhris, A. et al. Co-creation in the early stage of product-service system development. In: Procedia CIRP, v. 63, p. 27-32. Jul., 2017. 
Brunvand, S.; Hill, D. Gamifying your Teaching: Guidelines for Integrating Gameful Learning in the Classroom. In: College Teaching, v. 67, n. 1, 2019.

Chou, Y. Gamification \& Behavioral Design. Disponível em: https://yukaichou.com/. Acesso em abril de 2020.

Conforto, E. C.; Amaral, D. C.; Da Silva, S. L. Roteiro para revisão bibliográfica sistemática: aplicação no desenvolvimento de produtos e gerenciamento de projetos. In: Anais do $\mathbf{8}^{\mathbf{o}}$ Congresso Brasileiro de Gestão e Desenvolvimento de Produto - CBGDP, 2011.

Çeker, E.; Özdamh, F. What "Gamification" is and what it's not. In: European Journal of Contemporary Education, v. 6, n. 2, 2017.

Ferrari, B.; Fidanboylu, M. How crowdsourcing and open innovation could change the world: tapping into the ideas offered by large numbers of people seems a smart way to solve some of our most pressing problems. In: Guardian sustainable business technology and innovation. 2013. Disponível em: http://www.theguardian.com/sustainable-business/crowdsourcingopen-innovation-change-world. Acesso em: fevereiro de 2020.

Hitchens, M.; Tulloch, R. A gamification design for the classroom. In: Interactive Technology and Smart Education, v. 15, n. 1, 2018.

Hung, A. C. Y. Gamification as Design Thinking. In: International Journal of Teaching and Learning in Higher Education, v. 30, n. 3, 2018.

Kaulio, M. Customer, consumer and user involvement in product development: A framework and a review of selected methods. In: Total Quality Management, v. 9, n. 1, p. 141-149, 1998.

Kingsley, T. L.; Grabner-Hagen, M. M. Vocabulary by Gamification. In: The Reading Teacher, v. 71, n. 5, 2017.

Lacerda, D. P.; Dresch, A. Proença, A. Antunes Junior, J. A. Design Science Research: método de pesquisa para a engenharia de produção. In: Gest. Prod., São Carlos, v. 20, n. 4, p. 741 $761,2013$.

Magro, C. G.; Peña, M. L. M.; Garrido, E. D. PROTOCOL: Gamify a subject without advanced technology. In: Working Papers on Operations Management, v. 10, n. 2, 2019.

Marshall, C., Rossman, G. B. Designing qualitative research. Thousand Oaks: CA, 1995.

Martini, A.; Massa S.; Testa, S. Customer co-creation projects and social-media: the case of Barilla Italy. In: Business Horizons, v. 57, p. 425-434, 2014.

Mora, A.; Riera, D.; González, C.; Arnedo-Moreno, J. Gamification: a systematic review of design frameworks. In: Journal of Computing in High Education, 2017.

Schmitz, M.; Dickie, I. B. Abordagens participativas em projetos de design: uma Revisão Bibliográfica Sistemática em periódicos brasileiros. In: Anais do Gampi Plural '17. Joinville: Univille, 2017.

Turkish Language Association - Türk Dil Kurumu (2017). Oyun. Acesso em 20/03/2020, disponível em http://www.tdk.gov.tr

Vogt, W. P. Dictionary of statistics \& methodology: A nontechnical guide for the social sciences Thousand Oaks: London, New Delhi, 1999.

\section{Sobre os autores}

\section{Isadora Burmeister Dickie}

Doutora em Design pela UFPR, Mestre em Design pela UFSC e Bacharel em Design pela Univille. É professora adjunta da Univille desde 2010, atuando nos Cursos de Design e CST em Fotografia. Dentre os principais temas de ensino, pesquisa e extensão trabalhados, estão: Gestão 
de Design e Design Estratégico; Design, Ética e Sustentabilidade; Pesquisa em Design; CrowdDesign; Ensino-Aprendizagem; Gamificação, dentre outros.

isadora.dickie@gmail.com

\section{Haro Ristow Wippel Schulenburg}

Doutorando em Design na linha de Mídia, UFSC 2020. Mestre em Design na linha de Hipermídia pela UFSC 2012. Especialista em Design Gráfico e Estratégia Corporativa pela Univali 2008. Graduado em Design com Habilitação em Programação Visual pela Univille 2006. Desde 2008 atua como professor colaborador na Univille (Universidade da Região de Joinville) para os cursos de Design, harodesigner@gmail.com

\section{Luiz Paulo de Lemos Wiese}

Mestre em Farmácia pela UFSC, Especialista em Farmácia Magistral pela Univali e Bacharel em Farmácia pela UFSC. É professor adjunto da Univille desde 2008, atuando nos Cursos de Farmácia, Medicina, Enfermagem e Naturologia e coordenador do curso de especialização em Farmácia Clínica e Prescrição Farmacêutica e do projeto de extensão Riscos da Automedicação na Univille.

luizwiese@gmail.com 